\title{
FLOREAL RECABARREN ROJAS (21 DE ABRIL 1927-16 DE JUNIO 2020)
}

\author{
Sergio González Miranda*
}

Tengo la imagen de Floreal con su sonrisa en mi mente y me persiguen esas historias que amenamente contó acerca de los hermanos Domingo y Máximo Latrille Loustauneau, José Santos Ossa y especialmente la de Pedro López Gama y Barón Arnoux de la Riviere, cuando ambos organizaron una expedición a cargo de José Méndez, El Cangalla, el descubridor del mineral de plata de Caracoles. Me pregunto dónde estarán los escritos de esas historias maravillosas.

Floreal Recabaren Rojas fue sobre todo un historiador y un gran narrador, pero tuvo una vocación de servicio público que le llevaron hacia otros senderos. Fue regidor, alcalde, diputado, etc., una figura pública de Antofagasta, lo que tradicionalmente se denomina "un prohombre".

Más de una vez le pregunté por qué no se había dedicado por completo a ser historiador. $\mathrm{Su}$ respuesta era siempre una sonrisa, pues sabemos con Max Weber que la política y la ciencia son una vocación. Algunos, como Floreal, sintieron dos veces ese llamado.

Existen ciertos periodos en la historia de un territorio, puede ser una ciudad o región, donde florecen sus intelectuales. Tarapacá tuvo ese momento a fines del siglo XIX cuando se creó El Ateneo que reunió a intelectuales que nos heredaron obras que todavía se consultan. Antofagasta, igualmente, en la segunda mitad del siglo XX, tuvo a un selecto grupo de intelectuales que se destacaron en diferentes áreas de la cultura. Mario Bahamonde tuvo la intuición de ello y se abocó, con la colaboración de otros académicos, a elaborar una Guía de la Producción Intelectual Nortina. Editada en 1972 fue destacada en la prensa regional por la pluma del poeta Andrés Sabella, otro gigante de esa generación.

La década de los años 1960 fue notable para Antofagasta, estaba el teatro universitario con Pedro de la Barra. Se había fundado la Escuela Normal. Ese año el colegio San Luis inició su expansión con un nuevo edificio. Allí estudiaron varios premios nacionales en diversas áreas de las ciencias y las humanidades. Floreal que había sido alumno de Mario Bahamonde en el liceo de hombres de Antofagasta, fue su rector en 1965. Estudió Pedagogía en Historia y Geografía en el Instituto Pedagógico de la Universidad de Chile recibiéndose en 1954, con la tesis "Historia del proletariado de la provincia de Antofagasta de 1884 a 1919". También publicó en 2003 La matanza de San Gregorio: 1921, crisis y tragedia por la editorial LOM. Inició su carrera académica como profesor en la Universidad del Norte, pero su vocación política fue más fuerte. Pudo compartir con Óscar Bermúdez, Juan Panadés, Mario Cortés, Ottorino Ovalle, José A. González, entre otros, y recibir el reconocimiento de historiador.

Su generosidad la recuerdo como un tesoro, cuando le conté que estaba investigando el Cantón Salitrero Central o Bolivia, me envió un Excel con toda la información recopilada y organizada durante años.

Hasta no hace mucho me preguntó por datos sobre Gatico, donde se procesaba y exportaba la producción de cobre de una mina llamada Toldo, porque estaba investigado este misterioso poblado costero. También me compartió un cuaderno de campo de un ingeniero norteamericano respecto del nitrato de soda. Siempre inquieto, en 2016 estuvo participando del proyecto que rescataba las actas de la Municipalidad de Antofagasta, una colección que se inicia en 1872 y hasta 1910 . Un proyecto patrimonial fundamental.

La pregunta es si existen nuevas generaciones de historiadores e investigadores en Antofagasta, después de que esa ciudad tuviera tantos y de tan alto nivel intelectual, donde algunos todavía están plenamente vigentes en las universidades de la región. Me saltan algunos nombres de jóvenes que pueden recoger esa desafiante posta, es el caso del

\footnotetext{
* Universidad de Tarapacá, Instituto de Alta Investigación (IAI, Universidad de Tarapacá, sede Iquique. Correo electrónico: pampino50@gmail.com
} 
historiador tocopillano Damir Galaz-Mandakovic, entre otros.

Con Floreal Recabarren, nos dijo adiós un sabio de la historia de Antofagasta. Tenía un Café en el paseo peatonal Manuel Antonio Matta, donde se reunía con sus amigos de siempre para compartir una conversación plena de erudición. Floreal es un símbolo que perdurará como el Ancla antofagastina. 